\title{
Efficacy of Tranexamic Acid in Reducing Blood Loss during and After Caesarean Section: A Case control Study
}

\author{
Sinha $\mathrm{K}^{1}$, Pandey $\mathrm{S}^{2}$, Khadka $\mathrm{D}^{3}$
}

\section{ABSTRACT}

Introduction: The incidence of caesarean section is increasing day by day. One of the most common complications is primary or secondary postpartum haemorrhage. Tranexamic acid has been shown to be very useful in reducing blood loss and incidence of blood transfusion in varieties of surgery. Aim: To study the efficacy of tranexamic acid in reducing blood loss during and after the lower segment caesarean section. Methods: Arandomized, case controlled, prospective study was conducted on 100 women undergoing lower segment caesarean section carried out in the Department of Obstetrics and Gynaecology, Nepalgunj Medical College, Kohalpur from Sept 2019 to Feb 2020.Fifty of them were given tranexamic acid immediately before lower segment caesarean section and were compared with 50 others to whom tranexamic acid was not given. Blood loss was collected and measured during two different time interval. The first period was considered from placental delivery to end of lower segment caesarean section and second from the end of lower segment caesarean section to 2 hours postpartum period. Vital signs at time of delivery, at 1 hour and 2 hour postpartum and APGAR score at 1 min and 5 min were studied in both the groups. Result: Tranexamic acid significantly reduced the quantity of blood loss from the placental delivery to 2 hours post-partum: $360.9 \mathrm{ml}$ in the study group, versus $443 \mathrm{ml}$ in the control group $(p=0.0008)$.It also significantly reduced the quantity of blood loss from the end of lower segment caesarean section to 2 hours postpartum: $71.5 \mathrm{ml}$ in the study group versus $112.6 \mathrm{ml}$ in the control group $(p=0.0002)$.There was $18 \%$ less incidence of postpartum haemorrhage, who received tranexamic acid $(p=0.02)$.There were no significant adverse drug reaction and difference in APGAR score in both the groups. No complications or side effects were reported in either group. Conclusion: Tranexamic acid is safe and effective in reducing blood loss among women undergoing lower segment caesarean section.

Keywords: Antifibrinolytic, Lower segment Caesarean section (LSCS), Postpartum haemorrhage (PPH), Tranexamic acid

Authors:

1. Dr. Kavita Sinha

2. Dr. Subhash Pandey

3. Dr. Dipendra Khadka

${ }^{1}$ Department of Obstetrics \& Gynaecology, Nepalgunj Medical College Teaching Hospital, Kohalpur, Banke

${ }^{2}$ Department of Emergency \& General Practice, Bardiya Hospital, Bardiya

${ }^{3}$ Department of Medicine, Nepalgunj Medical College Teaching Hospital, Kohalpur, Banke

Address for Correspondence:

\author{
Dr. Kavita Sinha \\ Department of Obstetrics \& Gynaecology \\ Nepalgunj Medical College Teaching Hospital \\ Kohalpur, Banke, Nepal \\ Email: ksinhapandey@gmail.com
}

\section{INTRODUCTION}

The incidence of caesarean section is increasing day by day. The incidence of complications is much higher when compared with normal vaginal delivery. Out of these complications primary and secondary postpartum haemorrhage (PPH) is most common. It leads to increased maternal morbidity and mortality. Effect of this complication is reduced by reducing the amount of blood loss during and after caesarean section. ${ }^{1}$ An evidence based approach is to minimize peri-operative bleeding through the prophylactic use of the antifibrinolytic agents Aprotinin, Tranexamic acid and Epsilon animocaproic acid. ${ }^{2}$
Blood loss frequently leads to transfusion of allogeneic blood products, which expose patients to the risk of transfusion - related adverse effects such as febrile, non-haemolytic transfusion reactions, transfusion errors and blood born infections. Concerns about blood safety, continual blood shortages and rising costs of blood bank have generated interest in the reduction of transfusion requirements during and after surgery. Tranexamic acid is a synthetic derivative of the amino acid lysine that exerts its antifibrinolytic effect through the reversible blockade of the lysine binding sites on plasminogen molecules. ${ }^{3,4}$ It almost completely blocks the 
interaction of plasminogen and heavy chain of plasmin with the Iysine residues of fibrin monomer. ${ }^{5}$ Intravenous administration of tranexamic acid has been routinely used for many years to reduce haemorrhage during and after surgical procedures.

After an intravenous dose of $1 \mathrm{gm}$ tranexamic acid, the plasma concentration time curves show riexponential decay with a half-life of about 2 hours for the terminal elimination phase. Urinary excretion is the main route of elimination via glomerular filtration. Overall, renal clearance is equal to plasma clearance (110 to $116 \mathrm{ml} / \mathrm{min}$ ) and $90 \%$ excreted at 24hours after IV administration. ${ }^{6}$ It passes though the placenta as well. ${ }^{7}$ This study was conducted to demonstrate the efficacy of tranexamic acid on blood loss during and after LSCS.

\section{METHODS}

A randomized, case controlled, prospective study was conducted on 100 women undergoing lower segment caesarean section (LSCS) carried out in the Department of Obstetrics and Gynaecology, Nepalgunj Medical College, Kohalpur from Sept 2019 to Feb 2020. Ethical approval was taken from Institutional review committee (IRC), Nepalgunj Medical College and written informed consent was taken from each patient.

Full term primigravida or multigravida with singleton pregnancy delivered by LSCS with normal or abnormal presentation was included in this study. The following cases were excluded from the study: allergy to tranexamic acid, history of thromboembolic event, placenta praevia, placenta abruption, Pregnancy Induced Hypertension, multiple pregnancies, polyhydroamnios, macrosomia, any medical and surgical problems and any blood dyscrasia. Total cases enrolled were 100 which were allocated in 2 groups and tranexamic acid given on basis of lottery system, picked up by anaesthetic team, before starting the Surgery.

1. Study group (50) - subjects who received tranexamic acid

2. Control group (50) - subjects who did not received tranexamic acid

Preparation of tranexamic acid injections solutions, $1 \mathrm{gm} / 10 \mathrm{ml}$ tranexamic acid diluted with $10 \mathrm{ml}$ of distilled water. 20 minutes before incision, $1 \mathrm{gm}$ of tranexamic acid intravenous slowly infuse over 5 minutes. After delivery of neonate oxytocin 10 units in a pint of DNS was given by IV over 30mins.

Clinical Observations of vital signs- Blood Pressure, Respiratory rate and heart rate were measured immediately after placental delivery and 1 and 2 hours after birth respectively. The extent of PPH-Blood was measured by weight and volume following placental delivery to completion of skin closure and from completion of skin closure to 2 hours after birth. Side effects after giving tranexamic acid were noted. Laboratory examinations- pre operation haemoglobin, packed cell volume, Bleeding Time, Clotting Time, urine analysis were sent.
Blood was collected by a suction container and soaked gauze pads. Blood was measured post-partum during two separate periods from placental delivery to 2 hours postpartum. Amniotic fluid and amount of blood loss before delivery was not included in this study.

\section{Calculation of blood loss}

The quantity of blood $(\mathrm{ml})=$ (weight of material used after surgery- weight of material used prior to surgery) +(volume sucked in suction bottle after placental delivery).In addition, the pads used after completion of LSCS to 2 hour postpartum were separately weighed.

Data collected in structured proforma were entered in Microsoft Excel, compared by using chi-square test and statistical analysis was done with SPSS version 20.

\section{RESULTS}

\begin{tabular}{|ccccc|} 
Variables & $\begin{array}{c}\text { Study group } \\
\text { (mean } \pm \text { SD) N=50 }\end{array}$ & $\begin{array}{c}\text { Control group } \\
\text { (mean } \pm \text { SD) N = 50 }\end{array}$ & $\begin{array}{c}\mathbf{z} \\
\text { test }\end{array}$ & p-value \\
\hline Age (years) & $23.62 \pm 3.429$ & $24.5 \pm 3.982$ & 1.19 & 0.239 \\
\hline Height $(\mathrm{cm})$ & $152.56 \pm 5.75$ & $153.2 \pm 6$ & 0.54 & 0.588 \\
\hline Weight $(\mathrm{kg})$ & $52.54 \pm 7.86$ & $53.5 \pm 7.45$ & 0.63 & 0.532 \\
\hline
\end{tabular}

Table I : Distribution based on patient characteristics in both groups

Mean age was 23.62 years in the study group and 24.5 years in the control group. The difference in age, height and weight of both the groups were not statistically significant.

\begin{tabular}{|lcccc|}
\hline \multicolumn{1}{|c}{ Duration } & $\begin{array}{c}\text { Study group } \\
\text { mean blood } \\
\text { loss(ml) }\end{array}$ & $\begin{array}{c}\text { Control } \\
\text { group mean } \\
\text { blood loss } \\
\text { (ml) }\end{array}$ & $\begin{array}{c}\mathbf{z} \\
\text { test }\end{array}$ & $\begin{array}{c}\text { p- } \\
\text { value }\end{array}$ \\
\hline $\begin{array}{l}\text { Time of placental delivery } \\
\text { to completion of skin } \\
\text { closure }\end{array}$ & $289.4 \pm 71.4$ & $328.4 \pm 58.9$ & 2.98 & 0.004 \\
\hline $\begin{array}{l}\text { From completion of skin } \\
\text { closure to 2 hrs postpartum }\end{array}$ & $71.5 \pm 53.6$ & $112.6 \pm 51.7$ & 3.9 & 0.0002 \\
\hline $\begin{array}{l}\text { Time of placental delivery } \\
\text { to 2 hrs postpartum }\end{array}$ & $360.9 \pm 110.3$ & $443 \pm 88.552$ & 4.17 & 0.0008 \\
\hline $\begin{array}{l}\text { Amount of blood loss }> \\
500 \mathrm{ml}(\mathrm{PPH})\end{array}$ & 6 & 15 & 2.27 & 0.02 \\
\hline
\end{tabular}

Table II : Comparison of blood loss from placental delivery to 2 hrs postpartum and Post-partum haemorrhage

Above table shows mean blood loss from placental delivery to 2 hours postpartum was statistically significant $(p=0.0008)$ in both groups. Incidence of PPH was significantly less ( $p=0.02)$ those receiving tranexamic acid. 


\begin{tabular}{|c|c|c|c|c|c|}
\hline \multirow{5}{*}{ 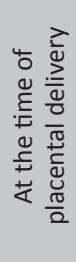 } & Vital signs & Study & Control & $z$ test & $\begin{array}{c}p- \\
\text { value }\end{array}$ \\
\hline & HR (bpm) & $86.14 \pm 7.25$ & $84.81 \pm 8.35$ & 0.86 & 0.394 \\
\hline & RR (breath/min) & $19.38 \pm 2.29$ & $19.94 \pm 2.14$ & 1.26 & 0.21 \\
\hline & SBP $(\mathrm{mm}$ of $\mathrm{Hg}$ ) & $121.08 \pm 10.1$ & $119.81 \pm 9.47$ & 0.65 & 0.514 \\
\hline & $\mathrm{DBP}(\mathrm{mm}$ of $\mathrm{Hg})$ & $77.08 \pm 7.04$ & $76.88 \pm 7.61$ & 0.14 & 0.892 \\
\hline \multirow{4}{*}{ 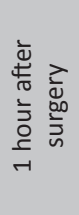 } & HR (bpm) & $86.14 \pm 7.05$ & $82.18 \pm 8.92$ & 2.46 & 0.066 \\
\hline & RR (breath/min) & $19.6 \pm 2.25$ & $19.98 \pm 2.49$ & 0.8 & 0.426 \\
\hline & SBP $(\mathrm{mm}$ of $\mathrm{Hg}$ ) & $\begin{array}{c}128.24 \pm \\
11.5\end{array}$ & $124.44 \pm 8.75$ & 1.32 & 0.065 \\
\hline & $\mathrm{DBP}(\mathrm{mm}$ of $\mathrm{Hg})$ & $80.48 \pm 6.77$ & $77.44 \pm 5.41$ & 1.36 & 0.08 \\
\hline \multirow{4}{*}{ 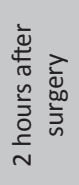 } & $\mathrm{HR}$ (bpm) & $79.96 \pm 7.55$ & $82.16 \pm 7.08$ & 0.36 & 0.094 \\
\hline & RR (breath/min) & $19.44 \pm 2.57$ & $19.58 \pm 2.75$ & 0.26 & 0.798 \\
\hline & SBP $(\mathrm{mm}$ of $\mathrm{Hg}$ ) & $127.16 \pm 12$ & $119.72 \pm 11.5$ & 0.465 & 0.647 \\
\hline & DBP $(\mathrm{mm}$ of $\mathrm{Hg}$ ) & $81.04 \pm 6.12$ & $78.28 \pm 5.39$ & 1.39 & 0.101 \\
\hline
\end{tabular}

HR: Heart rate, RR: Respiratory rate, SBP: Systolic blood pressure, DBP: Diastolic blood pressure

Table III : Table showing vitals of both groups at different interval

There was no statistically significant difference in vital signs at placenta delivery, 1 hour after delivery and 2 hours after delivery.

\begin{tabular}{|ccccc|}
\hline APGAR score & Study & Control & z test & p-value \\
\hline $1 \mathrm{~min}$ & $8.88+1.19$ & $8.64+1.34$ & 0.95 & 0.345 \\
\hline $5 \mathrm{~min}$ & $9.4+0.639$ & $9.22+0.79$ & 1.25 & 0.213 \\
\hline
\end{tabular}

Table IV: Comparison of APGAR score in both the groups

\begin{tabular}{|ccccc|}
\hline Adverse drug reactions & Study & Control & z test & p-value \\
\hline Nausea & 16 & 13 & 0.66 & 0.508 \\
\hline Vomiting & 09 & 08 & 0.08 & 1.135 \\
\hline Diarrhoea & 01 & 00 & 1.01 & 0.312 \\
\hline Signs of thrombosis & 00 & 00 & & \\
\hline
\end{tabular}

Table V : Comparison of adverse drug reaction in both the groups

No serious side effects noted in study group and difference in APGAR score in both the groups as shown in table IV and V.

\section{DISCUSSION}

Tranexamic acid exerts its antifibrinolytic effect by blocking the lysine binding locus of the plasminogen and plasmin molecules, thereby preventing the binding to the fibrin substrate. During placental delivery, fibrinogen and fibrin are rapidly degraded, whereas plasminogen activators and fibrin degradation products (FDP) increase due to activation of fibrinolytic system. This activation can last up to 6-10 hrs postpartum, causing more bleeding. It was because of this activation of fibrinolytic system that we decided to use tranexamic acid in this study. Our study showed that tranexamic acid significantly reduces bleeding from time of placental delivery to 2 hrs postpartum in LSCS which is comparable to the studies conducted by Ming- ying Gaiet al ${ }^{8}$, Gohel $\mathrm{M}$ et al ${ }^{9}$, Leila Sekhav at et al. ${ }^{10}$ Tranexamic acid also reduced the incidence of postpartum haemorrhage (patients with blood loss $\geq 500 \mathrm{ml}$ ) by $18 \%$ in study group as compared to control group. Ming-yingGai ${ }^{8}$, Zheng SR et al ${ }^{11}$ showed similar results.

There was no significant alteration in the vital signs of subjects following tranexamic acid administration at time of delivery and at $1 \mathrm{hr} \& 2 \mathrm{hrs}$ postpartum. Similar findings were reported by other studies too. ${ }^{8,10,11,12}$ In our study, there was no statistical difference in APGAR score at $1 \& 5$ minutes in both the groups, comparable observations were reported by Ming-yingGai et al ${ }^{8}$ and Zheng SR et al. ${ }^{11}$ The incidence of thrombosis during pregnancy \& puerperium is 5-6 times higher than that in the general population. When the anti-fibrinolytic drug tranexamic acid is administered, the increased risk of thrombosis should be considered, especially in the LSCS postpartum population. In our study, not a single patient developed signs of thrombosis; similar results were found in Ming-ying Gai ${ }^{8}$, Gohel Met al. ${ }^{9}$ The side effects of tranexamic acid as nausea, vomiting\& diarrhoea were not statistically significant in our study.

\section{LIMITATIONS}

The limitations of this study are smaller sample size and pitfall regarding measurement of actual amount of blood loss.

\section{CONCLUSION}

Tranexamic acid can be used safely in subjects with lower segment caesarean section. It significantly reduced the amount of blood loss during and after the operation and was not associated with any adverse side effects like nausea, vomiting, diarrhoea or thrombosis. Foetal outcome as evaluated by APGAR score was not adversely affected by use of tranexamic acid.

\section{REFERENCES}

1. SharmaR, NajamR, MisraM.K. Efficacy of Tranexamic Acid in Decreasing Blood Loss during and After Cesarean Section. Biomed Pharmacol J 2011; 4(1):231-235.

2. JaiprakashSahu, Nalini Mishra.Role of intravenous tranexamic acid in reducing blood loss during caesareanSection. J ObstetGynaecol Res. 2019 Apr; 45(4):841-848.

3. Irene Ray et al.Role of tranexamic acid on caesarean Blood loss.A Prospective Randomised Study.J ObstetGynaecol India.2016 Oct; 66(suppl 1):347-52.

4. Hoylaerts $M$, Linjen HR, Colleen D: Studies on mechanism of antifibrinolytic action of tranexamic acid. BiochemBiophysActa 1981; 673:75-85.

5. Okamoto $S$, Sato $S$, Takada $Y$ et al. An active stereo-isomer (transform) of amcha and its antifibrinolytic (Antiplasminic) action in vitro and in vivo. Kieo J Med 1964; 13:177-85. 
6. Walzman M, Bonnar J. Effects of tranexamic acid in human milk after oral administration of tranexamic acid in lactating women. Stockholm, Sweden: Kabi AB, 1971.

7. Walzman M, Bonnar J. Effects of tranexamic acid on the coagulation \& fibrinolytic systems in pregnancy complicated by placental bleeding. Arch Toxicol 1982; suppl.: 214-20.

8. Miya-yingGai, Lian-fang Wu, Qi-fengs Su. A clinical observation of blood loss reduced by tranexamic acid during \& after caesarean section: A multi centre randomized trial. European J ObstetGynaecol\& repro bio; 112(2004) 154-57.

9. Gohel M, Purvi P, Ashoo G, Pankaj D et al Efficacy of tranexamic acid in reducing blood loss during and after the lower segment cesareansection. A randomized case controlled prospective study. (ObstetGynecollndia.2007; 50(3); 228-230).

10. Leila Sekhavat, A. Tabatabaii, M. Dalili, et al. Efficacy of tranexamic acid in reducing blood loss after cesarean section. J of Mater-Fetal\& Neon Med; 22, 1 Jan 2009: 72 - 75.

11. Zheng SR, Yang HX, et al. Clinical study on the efficacy of tranexamic acid in reducing postpartum blood loss. Chin J ObstetGynecol 2001; 36:59

12. LoicSentilhes et al.Tranexamic acid for preventing postpartum hemorrhage after Cesarean delivery: a multicenter randomised doubleblind, placebo-controlled trial- a study protocol.BMC pregnancy Childbirth.2020.Jan 31; 20(1):63. 